\title{
PUBLIC HEALTH SISTEM IN SWEDEN
}

\section{Popescu Ljungholm}

\author{
Doina Popescu Ljungholm \\ Faculty of Law and Administration, Departament of Law and Public Administration \\ Pitesti University, Piteşti, Argeş \\ *Corespondence: Doina Popescu Ljungholm, Piteşti University, Tg. Din Vale St., Piteşti, \\ Argeş, Romania \\ Email:dopopescu@yahoo.com
}

\begin{abstract}
The Swedish health care system is a socially responsible system with an explicit public commitment to ensure the health of all citizens. Quality health care for all is a cornerstone of the Swedish welfare state. The 1982 Health and Medical Services Act not only incorporated equal access to services on the basis of need, but also emphasizes a vision of equal health for all. Three basic principles areintended to apply to health care in Sweden. The principle of human dignity means that all human beings have an equal entitlement to dignity, and should have the same rights, regardless of their status in the community. The principle of need and solidarity means that those in greatest need take precedence in medical care. The principle of cost-effectiveness means that when a choice has to be made between different health care options, there should be a reasonable relationship between the costs and the effects, measured in terms of improved health and improved quality of life.
\end{abstract}

Keywords: public health, equal acces, authorities, national level, local level.

\section{Introduction}

The present structure of the Swedish health care system reflects a long history of public funding and ownership, together with the growing importance of local self-government. Developments until the late 1960s were characterized by a growth in the number, size and importance of hospitals, largely determined by an expanding medical profession. During the 1960s, county councils' responsibility for hospital services became integrated with responsibility for mental health services and general outpatient services, previously a national government responsibility. By 1982, a new act formally handed over responsibility for the planning and provision of services to the county councils. During both the 1960s and the 1970s, health care expenditures and physical resources grew continuously. The chief concern at both the national and local government levels was to improve equal access to services. Since the late 1980s, attention has shifted to cost control and efficiency, and to a growing demand for performance and quality in more recent times. The Swedish health care system is organized into three levels: the national, regional and local. The Health and Medical Services Act of 1982 specifies that the responsibility for ensuring that everyone living in Sweden has access to good health care lies with the county councils/regions and municipalities. The Act is designed to give county councils and municipalities considerable freedom with regard to the organization of their health services. The state, through the Ministry of Health and Social Affairs, is responsible for overall health care policy. There are eight government agencies directly involved in the area of health care and public health: the National Board of Health and Welfare, the HSAN, the Swedish Council on Technology Assessment in Health Care. The 17 county councils and 4 regional bodies are responsible for the funding and provision of health care services to their populations. The 290 municipalities are legally obliged to meet the care and housing needs of older people and people with disabilities. There is a mix of publicly and 
privately owned health care facilities but they are generally publicly funded.. There are about 70 hospitals at the county level. ${ }^{1}$

\section{Organization levels of Swedish health system}

\section{A. National level}

The Ministry of Health and Social Affairs works to meet the objectives setby the Riksdag in the area of health care, health and social issues/insurance.This includes people's financial security, social services, health care, publichealth and the rights of children and people with disabilities. There are eightgovernment agencies directly involved in the area of health, medical care andpublic health: the National Board of Health and Welfare

the HSAN (Hälso- och Sjukvårdens Ansvarsnämnd), the SBU (Statens Beredning för Medicinsk Utvärdering), the MPA (Läkemedelsverket), the TLV(Tandvårds- och Läkemedelsförmånsverket), the Swedish Agency for Health and Care Services Analysis (Myndigheten för vårdanalys) and the National Institute for Public Health(Folkhälsoinstitutet), the Swedish Social Insurance Agency (Försäkringskassan).

The National Board of Health and Welfare is a large government agency, engaged in a wide range of activities in the areas of social services, healthcare services, environmental health, communicable disease prevention and epidemiology

The Medical Responsibility Board (HSAN) is a government agency that decides on disciplinary measures in the event of complaints or possible malpractice The Swedish Council on Health Technology Assessment - SBU is also a government agency who have the primary objective to promote the use of cost-effective health care technologies. The SBU has the mandate to review and evaluate health care technology from medical, economic, ethical and social points of view. Information on reviews of evidence is disseminated to central and local government officials and medical staff to provide basic data for decisionmaking

The Medical Products Agency is the Swedish national authority responsible for the regulation and surveillance of the development, manufacture and sale of drugs and other medicinal products. All drugs sold in Sweden must be approved by and registered by with the MPA. The TLV (formerly LFN until 2008) started its operation in October 2002 with the primary task of deciding if a medicine or medicinal product should be subsidized and included in the pharmaceutical benefits scheme. Since 2008, the TLV also has the mandate to decide which dental services should be subsidized. The TLV is also responsible for monitoring activities in the pharmacy market In the area of public health, the National Institute for Public Health is also a government agency under the Ministry of Health and Social Affairs. It is similar to the national government health departments that exist in many countries, but it reports both to the Minister of Health and Social Affairs and to an independent board of directors Regarding financial security, the Swedish Social Insurance Agency (Försäkringskassan) is the authority that administers the various types of insurance and benefits that make up social insurance in Sweden. Insurance benefits include sickness insurance, parental insurance, basic retirement pension, supplementary pension, child allowance, income support and housing allowance. The Agency is also engaged in work designed to prevent and reduce ill health through positive proactive action with the eventual goal of returning the person to the workforce. The Swedish Social Insurance Agency has a regional branch office in each county council that processes individual cases at the regional and local levels. ${ }^{2}$

The regional and local authorities are represented by the SALAR (Sveriges Kommuner och Landsting) at the national level. The SALAR was formed in 2007 by merging the Federation of Swedish County Councils (Landstingsförbundet) and the Swedish Association

\footnotetext{
${ }^{1}$ Diderichsen, Finn. Devolution in Swedish Health Care." Pub Med Central. British Medical Journal", London, 1999, p.22

2 Anders Amer,Health system in transition, The European Observatory on Health Systems and Policies, in partnership between the World Health Organization Regional Office for Europe,"Europe Monitor"Copenhag, 2005, p. 73.
} 
of Local Authorities (Svenska Kommunförbundet).The SALAR is a collaborative nationally oriented organization, representing all county councils/regions and municipalities in Sweden. The organization strives to promote and strengthen local self-government and provide local authorities with expert assistance. In addition, it serves as the employers' central association for negotiating terms of employment and local wage bargaining for the personnel employed by the county councils and municipalities. ${ }^{3}$

B. Regional level

At the regional level, the structure of care can be divided into primary care, district county council care (Länssjukvård) and regional care (Regionsjukvård). There are approximately 1100 primary care centres, about 70 district county council hospitals and 7 regional/university hospitals. The county councils have the overall responsibility for all health care services delivered (including dental care). The executive board of the county council, or an elected hospital board, decides how to organize the management. The county councils are grouped into six medical care regions (the Stockholm Region, the South-Eastern Region, the Southern Region, the Western Region, the Uppsala-Örebro Region and the Northern Region). These regions were established to facilitate cooperation in tertiary care among the county councils.Each region serves a population averaging more than 1 million people. Hospitals are primarily publicly owned. There are six private hospitals in the country of which three are notfor profit. The proportion of private primary care units varies substantially between the county councils.

\section{C.Municipal level}

The traditional organization of the municipalities involves a municipal executive board, a municipal council and several local government committees. The municipal executive board leads and coordinates the entire municipality's business and acts as a supervisor for the committees. The board is responsible to the municipal council for following up on matters that influence the development and economy of the municipality. The municipal council's duty is to make decisions about taxes, goals and budgets for all community-run businesses, and about the organization and tasks of the committees. The responsibilities of a municipality include issues relating to the immediate environment of the citizens, for example schools, social welfare services, roads, water, sewerage, energy, etc. Besides providing financial assistance, social services in Sweden cover child care, school health services, environmental hygiene, and care for older and disabled people and long-term psychiatric patients. Patients who have been fully medically treated and have been discharged from emergency care or geriatric hospitals also fall within the remit of the municipalities. There are both public and private nursing homes and home care providers.

\section{Decentralization and centralization}

Local self-government has a very long tradition in Sweden and is intended to create opportunities for development in service provision throughout the country. Decentralization of responsibilities within the Swedish health care system not only refers to relations between central and local government, but also to decentralization within each county council. Since the 1970s, financial responsibility has gradually been decentralized to providers within each county council. The county councils' financial and planning responsibility for health care services is clearly articulated in the 1982 Health and Medical Services Act, and has been further reflected in decentralization efforts within each county council. Changes in county council management systems reflect the goals and problems that county council politicians and responsible officials have encountered. The degree of decentralization, organization and management has come to vary considerably among county councils. As a result, the tradition of local self-government has led to regional differences in the governance and provision of health care between county councils. Local self-government is partly intended to create different solutions to service delivery rather than similar services in all county councils and

\footnotetext{
${ }^{3}$ Anna Glenngard,The swedish health care system, "Comm on wealth Fund", 2012, Stockolm, p. 153.
} 
regions. The strong tradition of local self-government has however also led to less favourable regional differences, for example with respect to the uptake of new medicines According to the Health and Medical Services Act of 1982, the county councils are expected to plan the development and organization of health care according to the needs of their residents. Thus, the county councils/regions make most of the resource-allocation decisions regarding health services within their geographical area. Traditionally, however, the central government and the county councils have collaborated extensively regarding planning and resource allocation for highly specialized regional (tertiary) health services and certain investments in high technology.

\section{Financing of Swedish health system}

Health care expenditure as a share of GDP was 9.9\% in Sweden since 2009. Health care is largely financed by tax in Sweden. About $80 \%$ of all expenditures on health are public expenditures. Both the county councils and the municipalities levy proportional income taxes on the population to cover the services that they provide. The county councils and the municipalities also generate income through state grants and user charges. About $4 \%$ of the population have VHI, in most cases paid for by their employer. Funding from VHI constitutes about $0.2 \%$ of total funding. About $17 \%$ of total funding of health expenditures is private expenditure, predominantly user charges. User charges for health care visits and per bed-day are determined by individual county councils and municipalities. In 2011, the fee for consulting a physician in primary care varied between SEK 100 and SEK 200 (€11-22). The fee for consulting a specialist at a hospital varied between SEK 230 and SEK 320 (€25-35). Patients are charged about SEK 80 (€9) per day of hospitalization. In almost all county councils, patients under 20 years of age are exempt from user charges. The government regulates high-cost protection schemes that cover health care outpatient visits. The national ceiling for out-of-pocket (OOP) payments means that an individual will never pay more than SEK $1100(€ 122)$ for health care visits within a period of 12 months. Co-payments for prescribed drugs are uniform throughout the country and fully regulated by the government. The patient pays the full cost for prescribed drugs up to SEK $1100(€ 122)$, after which level the subsidy gradually increases to $100 \%$. The maximum co-payment for prescribed drugs within a 12-month period is SEK 2200 (€244.The mechanisms for paying providers vary among the county councils, but payments based on global budgets or a mix of global budgets, case-based and performance-based payment are commonly used in hospitals. Payment to primary care providers is generally based on capitation for registered patients, complemented with fee-for-service and performance-based payments. The county councils pay the full cost for all inpatient drugs. For reimbursed prescription drugs, the county councils receive a government grant that is negotiated at central level between the SALAR and the government. ${ }^{4}$

\section{Health care services}

Most of the work in public health as well as other health-related work is carried out at regional and local levels in Sweden. The county councils manage the health care services while the municipalities manage areas such as compulsory and upper secondary education, pre-school, care for older people, roads and water, waste and energy. Sweden adopted a national public health policy in 2003, which states that public authorities should be guided by 11 objectives, covering the most important determinants of population health. The 11 public health objectives are:

1. participation and influence in society;

2. economic and social prerequisites;

3. conditions during childhood and adolescence;

4. health in working life;

5. environments and products;

\footnotetext{
${ }^{4}$ Hogberg, David. "Sweden's Single-Payer Health System Provides a Warning to Other Nations.", MacMillan Press, Stockolm, 2009, p. 65.
} 


\section{Popescu Ljungholm}

6. health-promoting health services;

7. protection against communicable diseases;

8. sexuality and reproductive health;

9. physical activity;

10. eating habits and food;

11. tobacco, alcohol, illicit drugs, doping and gambling.

Since 2005, there has been a new care guarantee in Sweden, which aims at strengthening the patient's position, improving accessibility and ensuring equal access to elective care in different parts of the country. The guarantee is based on instant contact (zero delay) with the health care system for consultation; seeing a general practitioner (GP) within seven days; consulting a specialist within 90 days; and waiting for no more than 90 days after being diagnosed to receive treatment. From July 2010, the guarantee is regulated by law and includes all elective care in the county councils. One important aim behind structural changes in Swedish health care since the 1990s has been a shift from hospital inpatient care towards outpatient care at hospitals and primary care facilities, respectively. Primary care, delivered by more than 1100 public and private primary care units throughout the country, involves services that do not require advanced medical equipment and is responsible for guiding the patient to the right level within the health system. For conditions requiring hospital treatment, medical services are provided at about 70 public hospitals at the county level and 6 private hospitals. Specialized somatic care involves health care services requiring medical equipment or other technologies that cannot be provided in the primary care setting. A relatively large proportion of the resources available for medical services has been allocated to the provision of care and treatment at hospital level. About two-thirds of the county hospitals are acute care hospitals, where care is offered $24 / 7$ and a larger number of clinical expert competences are represented than in local hospitals with more limited acute services. There is one private acute care hospital in the country. Several local hospitals have been transformed into specialized hospitals since the mid 1990s, offering elective treatments to a wider geographical area, but with no general acute services. Highly specialized care is provided at the seven public university hospitals. There are about 1200 pharmacies throughout the country, distributing prescription and non-prescription drugs to the population and to hospitals and other health services 5

\section{Health reforms in Sweden}

Reforms in Swedish health care are often introduced by local authorities in the form of county councils and municipalities. This means that the pattern of reform varies across local government, although mimicking behaviour usually occurs. During the past 10 years, reforms initiated by individual county councils have focused on developing primary care and coordinated care for older people. The number of private primary care providers has increased substantially, although public ownership of health centres is still the norm in most county councils. In parallel, restructuring of the hospital sector, involving specialization and concentration of services that were initiated in the 1990s, has continued. The governance and management of services have increasingly come to focus on comparisons of quality and efficiency. Reforms initiated at the national level have focused on the responsibilities of county councils and municipalities, more direct benefits for patient groups and regional equality of services. Key national reforms since the late 1990s have aimed at shortening waiting times for services. A new waiting-time guarantee was introduced in 2005 and has been regulated by law since 2010 . Several national reforms have also aimed to improve primary care, psychiatric care and coordination of care for older people. Since 2002, the TLV has had the responsibility of deciding if a prescription drug should be subsidized and included in the

\footnotetext{
${ }^{5}$ Glenngard, Anna H, Frida Hjalte, Marianne Svensson, et al. "Health Systems in Transition: Sweden." The European Observatory on Health Systems and Policies, in partnership between the World Health Organization Regional Office for Europe, "Europe Monitor" Copenhagen, 2005, p. 83.
} 
reimbursement scheme, based on information about the cost-effectiveness of various products. $^{6}$

The themes for refoms was:

- continued specialization and concentration of services within the hospital sector;

- regionalization of health care services including mergers between county councils;

- improved coordinated care, particularly for older people;

- more choice of provider, competition and privatization to support the development of primary care;

- privatization and competition in the pharmacy sector;

- changes in subsidies and co-payments for pharmaceuticals and in particular dental services;

- increased attention to public comparisons of quality and efficiency

\section{Conclusions}

Several recent changes in Swedish health system by anemerging performance paradigm in the governance and management ofhealth care. Key words related to the current and expected future trend are national quality registers, public comparison of quality and efficiency across local authorities and providers, value for money invested in health care, health outcomes and benefits from the patient perspective, process orientation and coordinated services. More attention is being paid to the need to establish valid performance indicators and to increase abilities to monitor performance on a regular basis by investments in registers and new information technology (IT) solutions. As a result of increased transparency, more attention is also directed towards differences in results and outcomes across regions and providers, and the learning opportunities that such differences provide. An important obstacle is the preference for local production across county councils, local hospitals and, not least, specialists themselves. Concentration of services to the regional hospitals is not always supported by outcome data available in the national quality registers. An emerging issue is the long-run financing of health care services

The objective of authorities was to improve services by integration between care and social services of the municipalities. In the last decade, a trend towards increased intervention from the national government can be noted. This is exemplified by new legislation regarding waiting times and patient safety and national financial incentives to promote the development of primary care, psychiatric care, care for older people and improved access to elective services.

\section{Bibliography}

Lofgran Ragnar.The swedish Health care system: Recent Reforms, Problems ans opportunities. Public Policy resources, no. 159, Fraser Institute, Stockolm, 2012;

Hogberg, David. Sweden's Single-Payer Health System Provides a Warning to Other Nations., MacMillan Press, Stockolm, 2009;

Anders Amer,Health system in transition, The European Observatory on Health Systems and Policies, in partnership between the World Health Organization Regional Office for Europe, Europe Monitor, Copenhagen, 2005;

Glenngard, Anna H, Frida Hjalte, Marianne Svensson, et al. "Health Systems in Transition: Sweden." The European Observatory on Health Systems and Policies, in partnership between the World Health Organization Regional Office for Europe,"Europe Monitor"Copenhag, 2005;

\footnotetext{
${ }^{6}$ Lofgran Ragnar.The swedish Health care system: Recent Reforms, Problems ans opportunities. "Public Policy resources", Fraser Institute, Stockolm, 2012, p. 116.
} 
Hjortsberg, Catharina, and Ola Ghatnekar. Health Care Systems in Transition: Sweden. European Observatory on Health Care Systems. World Health Organization, Europe Monitor, Copenhag, 2001;

Diderichsen, Finn. Devolution in Swedish Health Care Pub Med Central, British Medical Journal, London, 1999;

Anell Anders Health care reforms and cost containment in Sweden, Mossialos, Elias, and Julian Le Grand, Stockolm, 1999. 